\title{
THE INDO-AUSTRALIAN SPECIES OF THE ANT GENUS STRUMIGENYS FR. SMITH: GROUP OF S. GODEFFROYI IN BORNEO ${ }^{1}$
}

\author{
By William L. Brown, JR.
}

\section{Museum of Comparative Zoology, Harvard University}

This paper is a further contribution in a series which, when complete, will cover the known species of the IndoAustralian portion of the dacetine ant genus Strumigenys Fr. Smith. For general background, explanations of abbreviations used in citing measurements and indices, and discussion of $S$. godeffroyi Mayr and related species, see Brown, 1949, Mushi 20 : especially pp. 2 and 16-19. Previous parts of this series, the first two of which also include explanations of abbreviations for measurements, etc., are in Psyche 60: 85-89 (1953), 60: 160-166 (1954), 61: 68-73 (1954), 63: 113-118 (1956), and 64: 109-114 (1957). Figures of these species have been prepared, but are being saved for use in collective plates in connection with the eventual keys to all the Indo-Australian species of the genus.

I have seen a dealate female of $S$. godeffroyi Mayr from Long Navang, northern Borneo, E. Mjöberg leg. This species probably occurs at many coastal points and around settlements inland. It is widespread in the tropics of southeastern Asia and the Pacific.

The following five species evidently are much more local and rare.

\section{Strumigenys dyak sp. nov.}

Holotype worker: TL 3.07, HL 0.80. ML 0.35, wL $0.80 \mathrm{~mm}$.; CI 69, ML 44. Close to S. solifontis Brown, from Japan, but differing chiefly in the shorter and straighter mandibles, and in the long preapical tooth being set only a little more than half its own length away from the dorsal apical tooth. The size, proportions of the head, and shape of alitrunk are

1 Published with the aid of a grant from the Museum of Comparative Zoology at Harvard College. 
all as in solifontis, and even the pilosity of the two species is closely similar. The compound eyes of dyak are nearly twice the size of those of solifontis, and are more strongly convex and protruding laterally. Clypeus depressed and excised anteromedially.

Petiolar node as in solifontis, longer than broad and slightly longer than its peduncle; spongiform appendages well developed, but the lateral lobes not reaching the anterior nodal slope. Postpetiolar node smaller than that of solifontis, bare'y broader than long and only slightly broader than the petiole, its disc convex, smooth and shining, with a few short, weak longitudinal costulae along the anterior border. Unlike those of solifontis, the definitely smooth, shining areas on the sides of the alitrunk in dyak are restricted chiefly to the lower mesopleura. Basal gastric costulae somewhat spongiform, extending about $1 / 5$ the length of the basal tergite.

Ground pilosity of head rather sparse, consisting of subreclinate to obliquely erect, short, fine truncate hairs, becoming feebly spatulate on the free clypeal margin. Scape hair ; fine. directed apicad. Ground hairs of alitrunk rare, finc and inconspicuous, appressed to reclinate. About 6 longer, erect, fine truncate hairs bordering each occipital lobe laterally, posteriorly and medially; 3 pairs of the same on the alitrunk, the humeral pair being long and subflagellate. mesonotal pair long, pair on mid-pronotum not so long, inclined anteriorly. Sparse growth of long, fine erect hairs on petiole, postpetiole and gaster. Propodeal teeth acute and elevated, their infradental lamellae moderate in size, but expanded below and with a small growth of spongiform tissue laterally. Color ferruginous yellow (possibly faded); dorsum of head, except occipital lobes, faintly more pigmented. Mandibles and appendages light yellow, with redbrown teeth on the former.

Holotype a single worker from "head Camp, N. Borneo" (leg. E. Mjöberg, British North Borneo collecting tour), deposited in MCZ.

Paratype a single worker in MCZ, "foot of Mt. Murud," North Borneo (Mjöberg leg.). Size slightly smaller than in holotype, but proportions of head and mandibles identical. 
TL 2.8, HL 0.73 , wL $0.73 \mathrm{~mm}$. Color a trifle darker than in holotype.

This species can be separated from godeffroyi, indagatrix and other similar forms occurring in Borneo by its larger size; sparse, fine, largely erect pilosity; and slender, constricted alitrunk.

Strumigenys mjoebergi sp. nov.

Holotype worker: TL 2.4, HL 0.65 , ML 0.29 , wL $0.60 \mathrm{~mm}$; CI 68, MI 45. Very similar to $S$. godeffroyi, but differing slightly in size and proportions, and more strongly in sculpture, pilosity and color. Mandibles very slightly more curved than in godeffroyi, the preapical tooth long and extremely close to the apical fork; insertions rather widely spaced apart and the shafts robust. Alitrunk form much as in godeffroyi. Propodeal teeth acute, only weakly elevated. their infradental lamellae weakly convex below, thin and nearly transparent, without spongiform masses on their lateral faces. Petiolar node a little longer than broad, much as in godeffroyi, but the posterior and lateral spongiform appendages scanty. Postpetiolar node distinctly broader than petiolar node, a bit less than half as wide as the gaster, strongly convex, the surface densely punctulate-striate, opaque; spongiform appendages well developed, but less strong than in godeffroyi; much of the sides of the node free, especially the anterolateral surfaces. Gastric costulae coarse, numerous, extending $1 / 3$ or more the length of the basal gastric tergite; rest of gaster smooth. Alitrunk completely punctulate and opaque. Ground pilosity of head consisting of short decumbent hairs, narrowly spatulate or clavate, much heavier than in godeffroyi. Ground pilosity of a'itrunk fine, sparse, very inconspicuous, reclinate. A few short, stubby, erect spatulate or clavate hairs on the occipital lobes, a pair on the center of the pronotum, another on the mesonotum, and a longer humeral pair; sparse complement of distinctly spatulate erect hairs on nodes and gastris dorsum. Color sordid ferruginous yellow, dorsum of head. except occipital lobes, faintly darkened; gaster darker, brownish; lower halves of sides of alitrunk deep rec'dish brown; mandibles, antennae and legs yellowish.

Holotype [MCZ] from Nata Ragong, North Borneo (E. 
(Mjöberg leg.) without further data, but probably from rotten wood.

Paratype workers: 4 specimens with same data as for holotype [MCZ, USNM]. TL. 2.4-2.6, HL 0.68-0.71, ML. 0.290.30, WL. max. $0.68 \mathrm{~mm}$; ; CI 68-70, MI 43-44.

Paratype female: one dealate with same data as for holotype: TL 3.0 , HL 0.74 , ML 0.30 , WL $0.78 \mathrm{~mm}$.; CI 74 , MI 41 . Mesonotum evenly and densely punctulate throughout, without median sulcus or carina; bearing a few short, erect spatulate hairs. Scutellum convex, not strongly projecting. Anterior corner of mesanepisternum smooth and shining. Petiolar node broader than long. Sculpture of postpetiole and base of gaster stronger than in the worker, the latter extending half the length of the basigastric tergite in the middle. Other differences as usual for the caste; color like that of worker.

This species is distinguished from most godeffroyi group species by means of its striate, opaque postpetiolar disc. From the few forms with similar postpetiolar sculpture, mjoebergi differs in the position of the preapical tooth of the mandibles and in pilosity, other sculpture and color.

Strumigenys sublaminata sp. nov.

Holotype worker: TL 2.3, HL 0.61, ML 0.22 , wL $0.61 \mathrm{~mm}$.; CI 73, MI 36. A member of the godeffroyi group with rather short mandibles, similar to S. jepsoni Mann from the Fijis, but with more deeply excised posterior cephalic border and different sculpture and pilosity, etc.

Preocular laminae parallel, eyes convex, protruding laterally. Anterior clypeal border weakly concave in the middle. Mandibles stout, weakly arcuate and gently tapering toward apex. Teeth of apical fork subparallel, the ventral tooth a little more than half as long as the dorsal; two very indistinct intercalary denticles. Preapical tooth long and slender, about $2 / 3$ the length of the dorsal apical tooth and set about half or a little more its own length distant from the dorsal apical tooth. Inner border proximad of preapical tooth very feebly concave and with a faint indication of subcultrate (laminate) margination.

Anterior half of alitrunk convex above, posterior half a little lower but forming a completely continuous, very nearly 
straight (feebly convex) profile, without indication of metanotal groove. Propodeal teeth small, acute, subtended by ventrally broadened and convex lamellae without lateral spongiform facing. Petiolar node gently rounded above, longer than broad and slightly longer than its peduncle, its spongiform appendages limited to a moderate posterior rim and an anteriorly lobate midventral strip. Postpetiolar disc convex, about half again as broad as long and approximately half as broad as the gaster, with well developed appendages. Gaster narrow; basal costulae very short, somewhat spongiform in consistency. Postpetiolar disc, gastric dorsum, fore coxae, propodeal declivity and lower halves of sides of alitrunk nearly or quite smooth, strongly shining. Remainder of body densely punctulate, opaque; pronotum laterally with weak substriation.

Ground pilosity of head consisting of fairly conspicuous short, subreclinate spatulate hairs, anteriorly directed, forming regular fringes on anterior dorsal scrobe borders, anteior clypeal border and anterior borders of scapes, here directed toward scape apices. Promesonotum and dorsal surfaces of mandibles with similar hairs, but less conspicuous, directed mesad. Erect and inclined pilosity of short, stiff hairs with distinctly spatulate apices: 6 fringing posterior occipital margin, one on each lateral occipital margin, one pair on humeri and one pair on mesonotum, sparse rows of 4 each on petiole, postpetiole and gastric dorsum. Ventral side of head, and gaster near apex, with a few short fine hairs. Pilosity of appendages rather sparse, fine, subreclinate. Color rather uniform light ferruginous.

Holotype [MCZ] taken at 4000 feet altitude on Mt. Penrissen, Sarawak (Borneo) by E. Mjöberg, with no further data, but presumably from rotten wood. Seven paratype workers taken with the holotype [MCZ, USNM] show very little variation. TL 2.3-2.4, HL 0.61-0.63, ML 0.22 , WL 0.61 $0.62 \mathrm{~mm}$.; CI 70-73, MI 35-36. Certain specimens show a slight effacement of the pronotal punctulation, giving this region a subopaque appearance somewhat like that of $S$. godeffroyi.

The dealate female paratype, taken with the holotype, has a very high-bulking thorax; mesonotum densely and finely 
punctulate, without rugulation or median furrow, but with about 20 erect spatulate hairs. Petiolar node broader than long; otherwise, only the usual caste differences from the worker. TL 2.8, HL 0.65 , ML 0.24 , WL $0.72 \mathrm{~mm}$.; CI 77 , MI 37.

\section{Strumigenys indagatrix Wheeler}

Strumigenys indagatrix Wheeler, 1919, Bull. Mus. Comp. Zool. 63: 94, worker Type loc.: Kuching, Sarawak, Borneo [MCZ]. Cotypes (syntypes) in M. C. Z.

Cotypes, 2 workers: TL $2.5,2.5$; HL $0.60,0.60$; ML 0.32 , 0.32 ; WL $0.62,0.63 \mathrm{~mm}$.; CI 67,67 ; MI 53, 53. This species is extremely close to $S$. godeffroyi, and may even be only an extreme variant of that species. So far as can be told from the cotypes, indagatrix differs only in its slightly longer mandibles, slightly less well developed eyes and dorsal alitruncal pilosity, and somewhat more complete alitruncal sculpture; punctulation on pronotal dorsum and sides of alitrunk covers these areas completely and uniformly, without noticeable effacement.

Wheeler's treatment of this species could scarcely be more misleading. He regarded indagatrix as similar to S. mocsaryi, but said that "the mandibles are decidedly shorter," actually the reverse of the true situation. He then compared the species to four of five Strumigenys species described by Forel from Java in a paper published in 1905, saying that indagatrix was "smaller than any of them," a statement that does not hold well in the case of two of the species (signeae and ebbae). It is curious that of the four 1905 Forel species, none is very close to indagatrix, while the fifth (juliae), which Wheeler does not mention at all, is exceedingly close to both indagatrix and godeffroyi, if indeed it is separable at all. Wheeler's comparisons are all the more puzzling when one realizes that his collection contained samples determined by himself as both juliae and godeffroyi. $S$. indagatrix remains known only from the types, and until more samples turn up, it must remain doubtfully distinct from godeffroyi.

Strumigenys forficata sp. nov.

Holotype worker: TL 2.79, HL 0.68 , ML 0.23 , wL 0.74 
mm.; CI 73, MI 34. Maximum width across clypeus 0.27 $\mathrm{mm}$.

Similar to S. guttulala, but the head narrower behind, with narrower occipital lobes. Mandibles stout and short, like those of guttulata, but the inner borders convex and bearing narrower convex, translucent lamellae that do not quite meet at full closure. Preapical tooth large, flattened, distinctly recurved, translucent in texture, much as in the lamella. Dorsal apical tooth straight, slender and quite acute, but only about $0.05-0.06 \mathrm{~mm}$. long; ventral tooth stout, divergent, a little shorter than the dorsal tooth; 2 (possibly 3 ) intercalary denticles present. Antennal scrobes distinct, broad and deep, their dorsal borders distinctly produced laterally as slightly raised, anteriorly convex, thin but opaque lamellar borders. Center of head in region of vertex evenly convex; occipital lobes very feebly depressed. Posterior excision very broad, deep and semicircular, except that a broad, almost straight-edged translucent lamella fills its bottom, so that the excision appears broad and truncate in outline from dorsal view. Clypeus triangular, distinctly broader than long; posterior angle extended acutely, but narrowly rounded at the tip; anterior border very nearly straight, only very feebly depressed and concave medially. Eyes are small and situated at about the midlength of the head. Preocular laminae approximately straight and only feebly converging anteriorly.

Alitrunk rather narrow seen from above, only slightly wider across pronotum than through propodeum; anterior pronotal border narrowly rounded, with a projecting cultrate lamellar margin overhanging a deep transverse excavation in the dorsum of the cervix; anterodorsal margin of latter produced as a flange. Promesonotum in profile moderately convex; posterior mesonotum gently concave; metanotal groove obsolete; propodeal dorsum feebly convex. Propodeal teeth long, fine and spiniform, wholly enveloped in the thick, white opaque infradental lamellae, which are spongiform, broad but with irregular, feathery concave borders terminating in a higher ventral point. Since only the holotype is available, the feathery spongiform lamellar struct"re mav nocibly be an artifact, but there is nothing 
definite to indicate that other than the natural condition prevails.

Petiolar node quite high, shorter than its peduncle, with a narrowly rounded anterior summit and a gently convex sloping posterodorsal face; anterolateral surfaces excavated and the two carinae of the anterior nodal slope fused into one median carina which mitigates the steepness of the slope as seen from lateral view. These modifications render the lower part of the anterior nodal slope rather narrow or "pinched" as seen from the front. Seen from above, free portion of posterodorsal face oval, slightly longer than broad and narrowed in front. Posterior collar broad (damaged on left side) with large posterolateral lobes of feathery spongiform material; midventral spongiform strip well developed. Dorsolateral and lateral surfaces of node with some reclinate, feathery spatulate hairs partly obscuring surface. Postpetiolar disc transverse-ellipsoidal, convex, moderate in size, but nearly twice as broad as long and twice as broad as the petiolar node, with very well developed spongiform masses; periphery of the disc with a few inconspicuous, reclinate feathery-spatulate hairs.

Gaster with a dense pad of fine hairs anteroventrally and a dense, broad anterodorsal margin of spongiform material meeting that of the postpetiole. A band of numerous short filiform costulae extending from the anterior spongiform margin a short distance onto the surface of the first gastric tergite, otherwise smooth and shining. Posterior surfaces of occipital lobes. alitrunk (except for dorsal surfaces of mnnnotum and propndeum). most of petiolar node. postpetiolar disc, mandibles and fore coxae very nearly or quite smooth, shining. Clypeus subopaque. Most of head, entire mesonotum and dorsum of propodeum, scapes, most of legs and peduncle of petiole densely and finely punctulate, opaque or subopaque.

Entire dorsal pilosity consisting, with the few exceptions noted below, of moderately conspicuous appressed to decumbent spatulate or narrow cochlear hairs, those on the head abundant and uniform, directed anteriorly, diminishing on the occipital lobes toward the naked apices of the lobes; those on scape nearly appressed and directed apicad; those 
on clypeus smaller and finer than on rest of cephalic dorsum, forming an inconspicuous fringe anteriorly; those on promesonotum few, somewhat feathery in consistency. Gaster with a few small, subreclinate, anteromedially inclined subspatulate hairs along the anterior margin. Sparse, small fine hairs, mostly appressed or decumbent, on underside of head, on mandibles, legs, propodeal dorsum, venter of gaster and apex of gaster.

Color medium ferruginous ; mandibles, appendages, apices of occipital lobes, apex of gaster and both nodes lighter, yellowish. First gastric tergite medium reddish brown. Holotype a unique [MCZ] taken at Mt. Murud, North Borneo (E. Mjöberg leg.), no further data. 

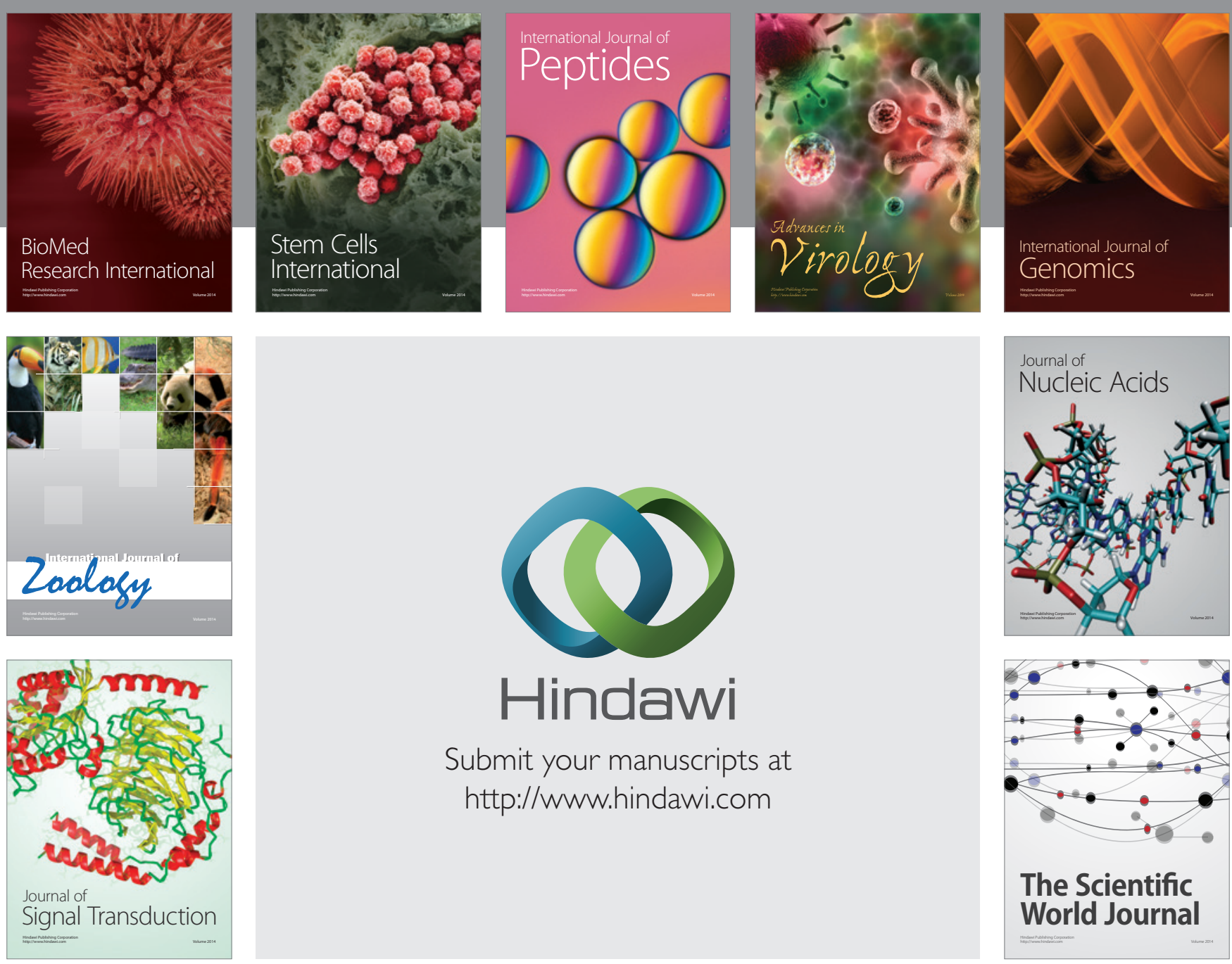

Submit your manuscripts at

http://www.hindawi.com
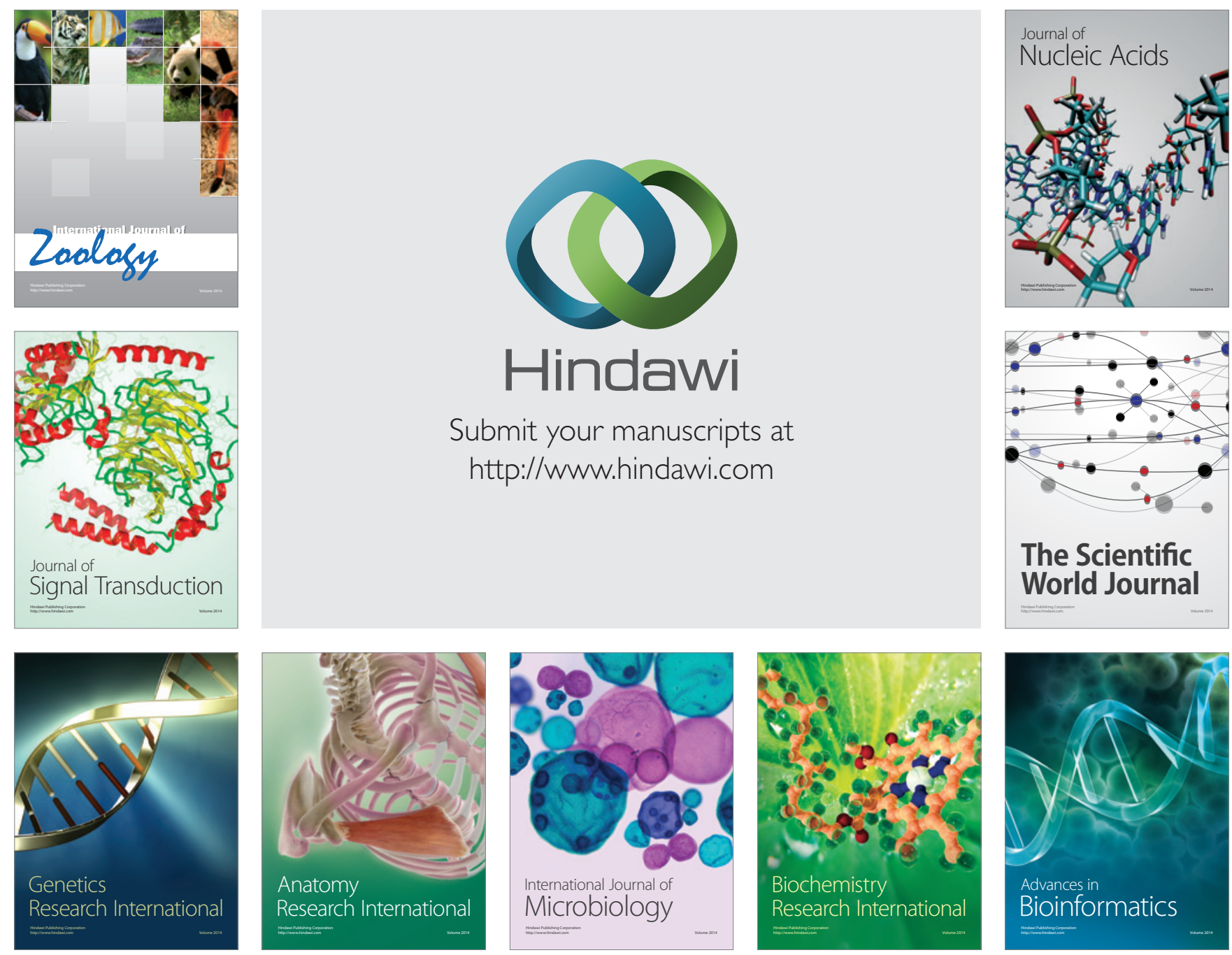

The Scientific World Journal
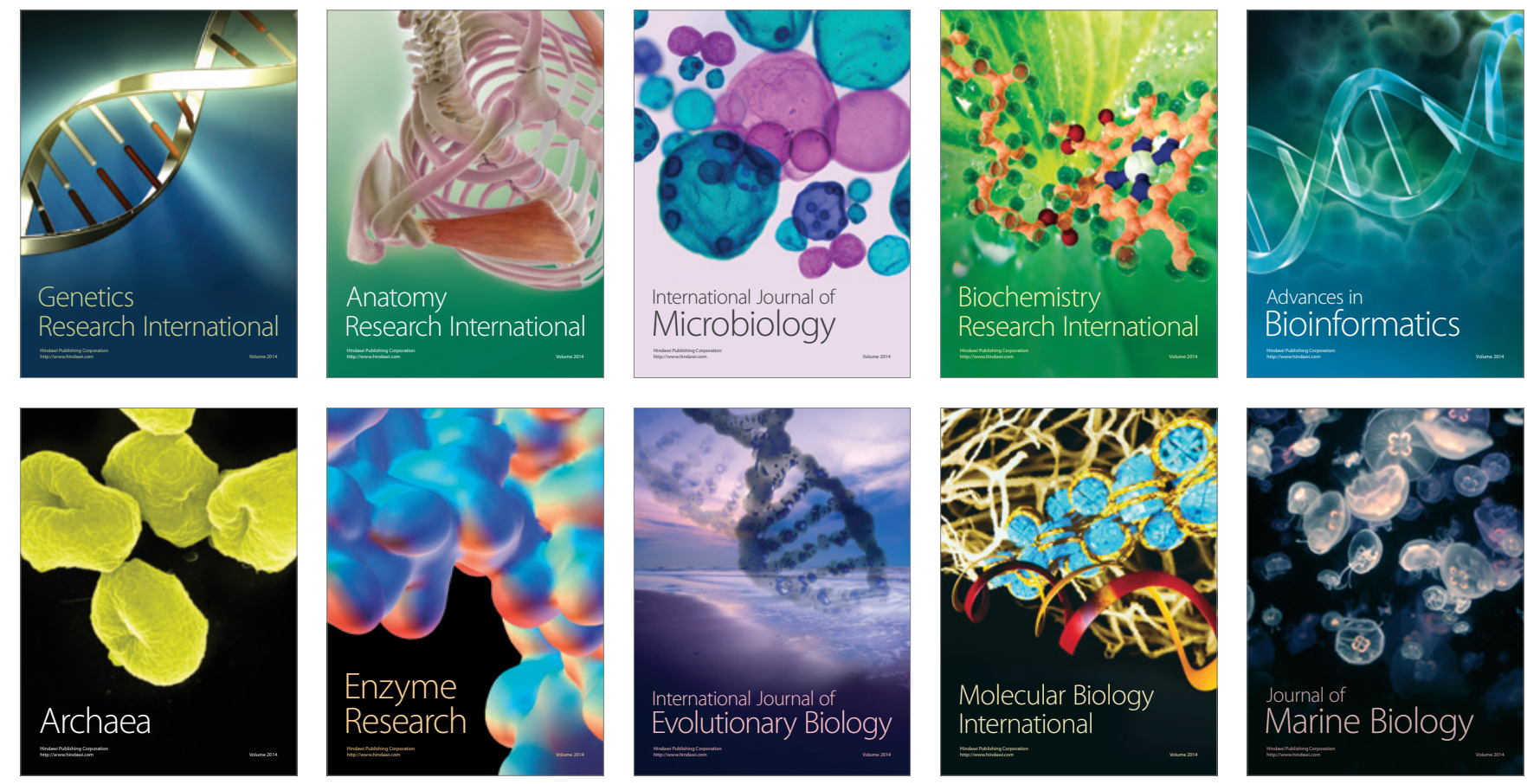